\title{
KARAKTERISTIK PAVING BERONGGA MENGGUNAKAN MATERIAL BATU KALI BULAT BERBASIS RAMAH LINGKUNGAN
}

\author{
Mirza Ghulam Rifqi, M. Shofi’ul Amin, Yuris Indra Lesmana \\ Jurusan Teknik Sipil Politeknik Negeri Banyuwangi, Jl Raya Jember Kilometer 13 Labanasem Kabat Banyuwangi, \\ 68461. \\ Email: mirza@poliwangi.ac.id.
}

\begin{abstract}
ABSTRAK
Paving merupakan salah satu bahan yang banyak digunakan sebagai perkerasan jalan, karena memiliki keandalan dalam hal kekuatan, keawetan serta kemudahan pemasangannya. Oleh karena itu, dengan perkembangan teknologi sekarang ini, dilakukan usaha untuk meningkatkan kinerja paving menjadi lebih efektif dan efisien sebagai bahan perkerasan jalan yaitu dengan cara membuat paving berongga yang memungkinkan aliran permukaan untuk infiltrasi ke dalam tanah.Penelitian dilakukan menggunakan metode experimen yaitu mengganti agregat halus dengan agregat kasar pada paving normal. Agregat batu kali bulat yang dipakai yaitu ukuran 5-10 $\mathrm{mm}$ dan $10-20 \mathrm{~mm}$. Setelah diketahui proposi yang tepat maka akan diuji dengan variasi perbandingan 1PC:4KR dan 1PC:6KR. Kemudian akan diuji kuat tekan, porositas dan permeabilitas dengan mengunakan metode constant head water permeability test.Hasil pengujian karakteristik paving berongga dapat berpenggaruh pada nilai karakteristik meliputi nilai berat jenis, porositas, permeabilitas dan kuat tekan pada umur 28 hari sebesar 2,146-2,206 gr/ $/ \mathrm{cm}^{3}$ untuk berat jenis, 16,44-17,11\% untuk porositas, 1,53-2,60 cm/s untuk permeabilitas dan untuk kuat tekan paving berongga sebesar 4,40-7,87 MPa, dari hasil pengujian didapatkan nilai permeabilitas dan kuat tekan yang tidak sesuai dengan yang disyaratkan SNI 03-0691-1996 dan ACI 522R-10 yaitu nilai permeabilitas 1,14$1,22 \mathrm{~cm} / \mathrm{s}$ dan nilai kuat tekan $<8,5 \mathrm{MPa}$, dikarenakan paving berongga dengan penggunaan material batu kali bulat memiliki nilai rongga yang besar sehingga paving berongga berpengaruh terhadap nilai permeabilitas dan kuat tekan, semakin besar nilai permeabilitas pada paving berongga memiliki nilai kuat tekan semakin rendah, maka paving berongga menggunakan material batu kali bulat tidak dapat digunakan karena tidak sesuai yang disyaratkan SNI 03-0691-1996 [1].
\end{abstract}

\section{Kata kunci :}

Kuat tekan, porositas, presentase pori, permeabilitas dan ramah lingkungan.

\section{PENDAhuluan}

Paving berongga (pervious paving) adalah salah satu jenis beton tanpa pasir yang terbuat dari campuran semen atau perekat hidrolis, agregat, air dan bahan lainnya tanpa mengurangi mutu dari paving berongga (pervious paving) tersebut. Paving berongga (pervious paving) dapat dimanfaatkan untuk keperluan jalan, pelataran parkir, trotoar, taman dan keperluan lainnya. Non Fine atau pervious concrete adalah beton yang dibuat dengan sedikit atau tanpa agregat halus (pasir). Hal ini membentuk paving atau beton dengan pori yang lebih banyak. Sifat pervious paving atau pervious concrete yang memiliki porositas tinggi menyebabkan air dapat melewati paving atau beton, sehingga dapat mengurangi run off dan dapat mengisi kembali air tanah [2]. Namun pervious paving atau pervious concrete dapat diterapkan pada jalan dengan beban lalu lintas yang rendah.

Pembuatan paving berongga pada umumnya terdiri dari campuran agregat halus, semen, dan air dengan perbandingan tertentu.Campuran paving berongga dapat juga ditambah dengan aditif untuk mendapatkan paving yang lebih kuat. Agregat yang digunakan dalam pembuatan paving berongga adalah agregat kasar batu kali bulat yang memiliki ukuran 5-10 mm dan $10-20 \mathrm{~mm}$, agregat tersebut sebagai pembanding yang berfungsi untuk mengetahui pengaruh gradasi dalam campuran paving berongga terhadap nilaipermeabilitas dan kuat tekan yang besar.

Adanya pori-pori yang terbentuk pada permukaan paving mengakibatkan kuat tekan paving berongga lebih rendah dari pada paving konvensional sehingga 
perkerasan paving berongga hanya diaplikasikan pada beban lalu lintas ringan seperti jalur pejalan kaki dan ruang terbuka hijau. Paving berongga merupakan suatu material jalan yang unik dan efektif yang ramah lingkungan.Dikatakan ramah lingkungan kerena paving tersebut dapat menangkap air hujan dan membiarkan air hujan meresap ke dalam tanah.Selain itu material paving berongga dapat mengisi cadangan air tanah dan mengurangi limpahan permukaan.

Penelitian ini dilakukan dengan tujuan untuk mengetahui pengaruh bentuk agregat kasar batu kali bulat dengan gradari $5-10 \mathrm{~mm}$ dan $10-20 \mathrm{~mm}$ dalam campuran paving berongga terhadap nilai porositas dan permeabilitas air. Sedangkan hasil penelitian ini diharapkan dapat dimanfaatkan untuk pembuatan paving berongga sebagai material konstruksi ramah lingkungan yang dapat berkontribusi untuk mengurangi adanya genangan air pada jalur pejalan kaki dan ruang terbuka hijau.

\section{STUDI PUSTAKA}

Paving menurut SNI 03-0691-1996 [1] merupakan salah satu komposisi bahan bangunan yang dibuat dari campuran semen portland atau bahan pelekat hidrolis sejenisnya, air dan aggregat dengan atau tanpa bahan lainnya yang tidak mengurangi mutu bata beton (pervious paving). Paving mulai dikenal dan dipakai di Indonesia terhitung sejak tahun 1977/1978, dimulai dengan pemasangan trotoar di Jalan Thamrin dan untuk terminal bis Pulogadung, keduanya di Jakarta, sekarang pemakaiannya sudah tersebar di seluruh kota di Indonesia. Baik digunakan sebagai perkerasan jalan perumahan atau kawasan pemukiman, memperindah taman, halaman rumah, perkerasan area parkir, halaman sekolah serta halaman kawasan hotel dan restoran [4].

Paving berongga akan dibuat seperti paving block yang banyak ditemui di pasaran dengan panjang 200$250 \mathrm{~mm}$, lebar 100-112 mm dengan ketebalan berkisar antara 60, 80, 100, 120 dan seterusnya. Untuk mengetahui porsi masing-masing bahan yang digunakan sebelum paving berongga dibuat di lapangan, biasanya dilakukan percobaan terlebih dahulu. Untuk menentukan porsi dari setiap bahan umumnya harus berdasarkan pada ketentuanketentuan sebagai berikut :

a) Kuat tekan yang ditentukan

b) Jenis tipe semen

c) Ukuran agregat d) Minimal besarnya faktor air semen

e) Kemudahan dikerjakan

f) Keadaan lingkungan

Kekuatan paving ditunjukkan pada Tabel 1.

Tabel 1. Kekuatan Fisik Paving

\begin{tabular}{|c|l|c|c|c|c|c|}
\hline \multirow{2}{*}{ Mutu } & \multirow{2}{*}{ Kegunaan } & \multicolumn{2}{|c|}{$\begin{array}{c}\text { Kuat Tekan } \\
\left(\mathbf{K g} / \mathbf{C m}^{2}\right)\end{array}$} & \multicolumn{2}{|c|}{$\begin{array}{c}\text { Ketahanan Aus } \\
(\mathbf{m m} / \mathbf{m e n i t )}\end{array}$} & $\begin{array}{c}\text { Penyerapa } \\
\mathbf{n} \text { air rata- } \\
\text { rata } \\
\text { maksimum }\end{array}$ \\
\cline { 3 - 7 } & & Rata-rata & Min & Rata-rata & Min & $(\mathbf{\%})$ \\
\hline A & Perkerasan Jalan & 400 & 350 & 0,0090 & 0,130 & 3 \\
\hline B & Tempat parkir mobil & 200 & 170 & 0,1300 & 1,149 & 6 \\
\hline C & Pejalan kaki & 150 & 125 & 0,1600 & 1,184 & 8 \\
\hline D & Taman kota & 100 & 85 & 0,2190 & 0,251 & 10 \\
\hline
\end{tabular}

Sumber : SNI 03-0691-1996

\section{METODELOGI}

Menentukan konsep penelitian, lalu dilanjutkan ke studi pustaka, pengumpulan material (semen dan kerikil) setelah itu pengujian kerikil yang akan digunakan pengujiannya meliputi uji berat jenis, kadar lumpur, Analisa ayakan, Impact test dan uji los angeles machine. Diagram alir penelitian ditunjukkan pada Gambar .

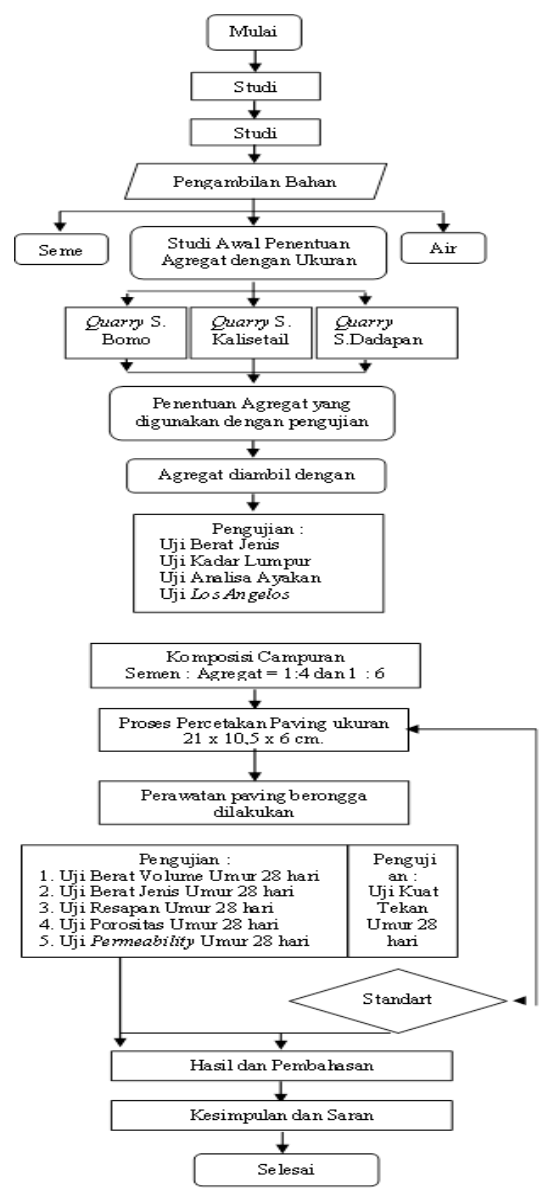

Gambar 1. Diagram alir penelitian 


\section{ANALISA DAN PEMBAHASAN}

Paving berongga dalam penelitian ini adalah terdiri dari komposisi semen, kerikil dan air dengan perbandingan $1 \mathrm{PC}: 4 \mathrm{KL}$ dan $1 \mathrm{PC}: 6 \mathrm{KL}$. Hasil dari penelitian paving berongga dapatdilihat padaGambar 1 dan Tabel 2. Sedangkan ilustrasi sampel permeabilitas ditunjukkan pada Gambar 2.

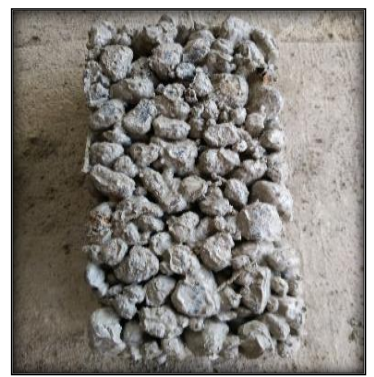

Gambar 1. Paving Berongga Berbentuk Pesegi

(Dokumentasi Praktikum, 2017)

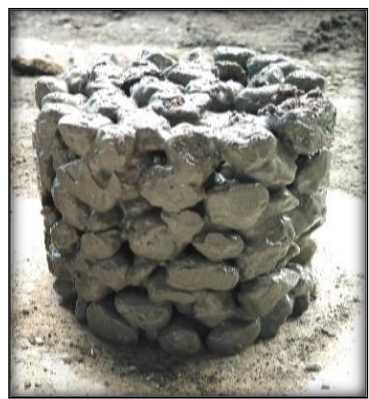

Gambar 2. Sampel uji permeabilitas

(Dokumentasi Praktikum, 2017)

Tabel 2Hasil Pengujian

\begin{tabular}{lcc}
\hline \multicolumn{1}{c}{ Pengujian } & Satuan & Nilai \\
\hline Berat jenis kerikil rata-rata & gram & 2.50 \\
Kadar lumpur & $\%$ & 0.87 \\
Angka kehalusan ayakan & $\%$ & 3.98 \\
Los Angelos & $\%$ & 26.80 \\
Impact Test & $\%$ & 11.83 \\
Berat Volume Paving & $\mathrm{gr}^{\mathrm{c}} / \mathrm{cm}^{3}$ & 1.883 \\
Berat Jenis Paving & $\mathrm{gr} / \mathrm{cm}^{3}$ & 2.032 \\
Resapan Paving Berongga & $\%$ & 8.531 \\
Porositas Paving Berongga & $\%$ & 16.928 \\
Permeabilitas Paving Berongga & $\mathrm{cm} / \mathrm{s}$ & 1.15 \\
Kuat Tekan Paving Berongga & $\mathrm{MPa}$ & 7.87 \\
\hline
\end{tabular}

Sumber : Hasil pembahasan 2017

\section{IV.1 Pengujian Nilai Permeabilitas Paving Berongga.}

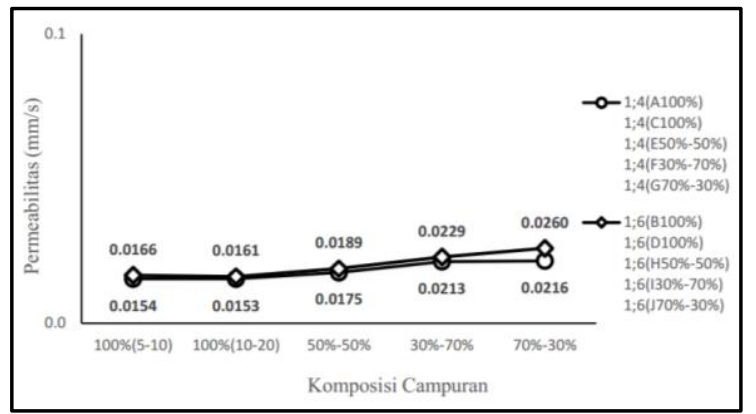

Gambar 3. Grafik Permeabilitas paving Berongga

(Hasil Analisa, 2017)

Dari Gambar 3diatasdapat dilihat pengujian permeabilitas paving berongga pada umur 28 hari dengan campuran $1 \mathrm{PC}: 4 \mathrm{KR}, 1 \mathrm{PC}: 6 \mathrm{KR}$ ukuran campuran 5-10 $\mathrm{mm}$ dan $10-20 \mathrm{~mm}$ didapat nilai permeabilitas yang berbeda, hal ini dikarenakan campuran dan pengaruh ukuran agregat yang membuat nilai permeabilitas berbeda dari setiap sampel benda uji. Nilai permeabilitas tertinggi pada campuran tipe $\mathbf{J}_{(70 \%-30 \%)}$ memiliki nilai permeabilitas $0,0260 \mathrm{~mm} / \mathrm{s}$ dan campuran tipe $\mathrm{G}_{(70 \%-30 \%)}$ memiliki nilai permeabilitas $0,0216 \mathrm{~mm} / \mathrm{s}$ dari permeabilitas tersebut nilai kuat tekan campuran tipe $\mathbf{J}_{(70 \%-30 \%)}$ memikili nilai permeabilatas tertinggi dikarenakan campuran yang digunakan memiliki proporsi campuran 1PC : 6KR sedangkan untuk campuran tipe $\mathrm{G}_{(70 \%-30 \%)}$ proporsi campuran yang digunakan 1PC : 4KR tetapi ukuran agregat yang digunakan sama yaitu campuran 5-10 dan 10-20 mm, sedangkan permeabilitas terendah terdapat pada campuran tipe $\mathrm{A}_{(100 \%)}$ dengan porporsi campuran 1PC : 4KR yaitu $0,0154 \mathrm{~mm} / \mathrm{s}$ dan campuran tipe $\mathbf{B}_{(100 \%)}$ dengan proporsi campuran 1PC : $6 \mathrm{KR}$ yaitu $0,0166 \mathrm{~mm} / \mathrm{s}$, jadi dari pengujian permeabilitas diatas dapat disimpulkan bahwa semakin besar ukuran agregat yang digunakan maka semakin besar nilai permeabitas yang diperoleh. Menurut ACI 522R nilai permeabilitas berkisar 0,0114 - $0,022 \mathrm{~mm} / \mathrm{s}$ jadi dapat disimpulkan bahwa semakin besar ukuran agregat yang digunakan maka semakin besar nilai permeabilitas.

\section{IV.2 Pengujian Nilai Kuat Tekan Paving Berongga.}

Dari Gambar 4diatas dapat dilihat pengujian kuat tekanpaving berongga pada umur 28 hari dengan campuran $1 \mathrm{PC}: 4 \mathrm{KR}, 1 \mathrm{PC}: 6 \mathrm{KR}$ ukuran campuran 5-10 $\mathrm{mm}$ dan 10-20 mm didapat nilai kuat tekan yang berbeda, hal ini dikarenakan campuran dan pengaruh 
ukuran agregat yang membuat kuat tekan berbeda dari setiap sampel benda uji.

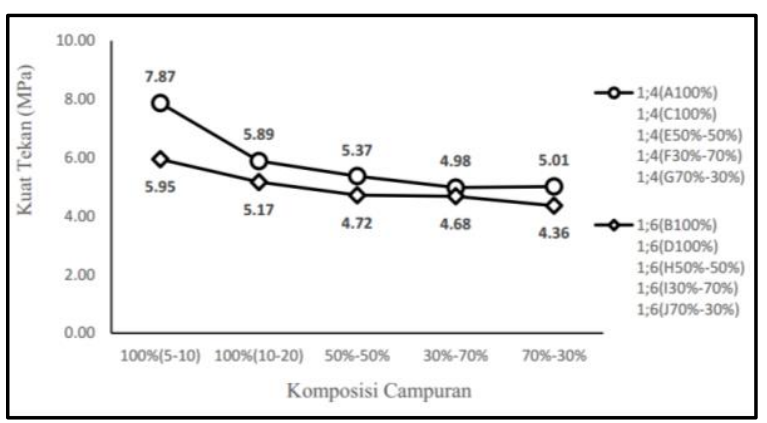

Gambar 4. Grafik Kuat Tekan paving Berongga

(Hasil Analisa, 2017)

Nilai kuat tekan tertinggi pada campuran tipe $\mathrm{A}(100 \%)$ memiliki nilai kuat tekan $7,87 \mathrm{MPa}$ dan campuran tipe $\mathrm{B}(100 \%)$ memiliki nilai kuat tekan 5,95 $\mathrm{MPa}$ dari kuat tekan tersebut nilai kuat tekan campuran tipe $\mathrm{A}(100 \%)$ memiliki nilai kuat tekan tertinggi dengan perbandingan campuran $1 \mathrm{PC}: 4 \mathrm{KR}$ sedangkan untuk campuran tipe $\mathrm{B}(100 \%)$ perbandingan campuran yang digunakan 1PC : 6KR tetapi ukuran agregat yang digunakan sama yaitu ukuran 5-10 mm, sedangkan nilai kuat tekan terendah terdapat pada campuran tipe $\mathrm{G}(70 \%-30 \%)$ dengan perbandingan campuran $1 \mathrm{PC}: 4 \mathrm{KR}$ yaitu 5,01 $\mathrm{MPa}$ dan campuran tipe $\mathrm{J}(70 \%-30 \%)$ dengan perbandingan campuran 1PC : 6KR yaitu 4,36 $\mathrm{MPa}$, jadi dari pengujian kuat tekan diatas dapat disimpulkan bahwa semakin kecil ukuran agregat yang digunakan maka semakin besar nilai kuat tekan yang diperoleh karena ukuran agregat dapat mempengaruhi nilai kuat tekan dalam penelitian ini karena penelitian ini hanya mengunakan campuaran kerikil dan semen tanpa ada bahan pengikat lainnya. Menurut SNI 03-0691-1996 nilai Kuat Tekan minimum paving untuk taman kota (Mutu D) paving harus memiliki nilai kuat tekan sebesar 8,5 $\mathrm{MPa}$. sehingga paving berongga dengan mengunakan agregat batu kali bulat tanpa campuran agregat halus tidak berpotensi sebagai perkerasan jalan dikarenakan paving berongga memiliki nilai kuat tekan rendah.

\section{KESIMPULAN}

Dari hasil pengujian karakteristik yang dilakukan terhadap paving berongga dengan menggunakan material batu kali bulat dengan variasi perbandingan 1PC:4KR dan 1PC:6KR ukuran seragam 5-10 mm dan 10-20 mm, maka dapat ditarik kesimpulan sebagai berikut :

Pengaruh agregat batu kali bulat tanpa menggunakan agregat halus terhadap pembuatan paving berongga dapat berpenggaruh pada nilai karakteristik paving berongga meliputi nilai berat jenis, porositas, permeabilitas dan kuat tekan pada umur 28 hari sebesar 2,146-2,206 gr/ $/ \mathrm{cm}^{3}$ untuk berat jenis, 16,44$17,11 \%$ untuk porositas, 1,53-2,60 cm/s untuk permeabilitas dan untuk kuat tekan paving berongga sebesar 4,40-7,87 $\mathrm{MPa}$, dari hasil pengujian didapatkan nilai permeabilitas dan kuat tekan yang tidak sesuai dengan yang disyaratkan SNI 03-06911996 dan ACI 522R-10 yaitu nilai permeabilitas 1,14$1,22 \mathrm{~cm} / \mathrm{s}$ dan nilai kuat tekan $<8,5 \mathrm{MPa}$, dikarenakan paving berongga dengan penggunaan material batu kali bulat memiliki nilai rongga yang besar. sehingga paving berongga berpengaruh terhadap nilai permeabilitas dan kuat tekan, semakin besar nilai permeabilitas pada paving berongga memiliki nilai kuat tekan semakin rendah, maka paving berongga penggunaan material batu kali bulat tidak dapat digunakan karena tidak sesuai yang disyaratkan SNI 03-0691-1996 [16].

\section{DAFTAR PUSTAKA}

[1] SNI (Standar Nasional Indonesia) 03-0691-1996 : Bata Beton (Paving Block). Dewan Standarisasi Nasional.Anonim, 1996.

[2] American Concrete Institute (ACI), Specification for Pervious Concrete Pavement. An ACI Standart.Reported by ACI Committee 522.

[3] Adi, K. 2013. Desain beton berpori untukperkerasan jalan yang ramah lingkungan. Universitas Sebelas Maret. Surakarta.

[4] Ari, D. (2013). Desain Beton Berpori untuk Perkerasan Jalan yang Ramah Lingkungan.Universitas Sebelas Maret.Surakarta

[5] Ariyani, D. (2015). Studi Pervious Paving untuk menurunkan runoff.Jurusan Teknik LingkunganFTSP-ITS. Surabaya.

[6] Eko, P. (2015). Pengaruh Gradasi Terhadap Porositas dan Kuat Tekan Beton Berpori. Universitas Sebelas Maret. Surakarta

[7] Erwanto, Z. (2014). Modul Praktikum Bahan Bangunan. Program Studi Teknik Sipil Politeknik Negeri Banyuwangi. Banyuwangi.

[8] Giang, T. (2015). Pengaruh Agregat Limbah Gerabah Terhadap Modulus of Rupture dan Kuat Tarik Belah pada Beton Pervious. Universitas Sebelas Maret. Surakarta

[9] Puji, A. (2014) Kuat Tekan, Porositas dan permeabilitas Perveous Concrete dengan Campuran agregat Limbah Gerabah. Universitas Sebelas Maret. Surakarta

[10] Standart Nasional Indonesia (SNI) 03-1973-1990, Metode pengujian berat isi Beton.

[11] Standart Nasional Indonesia (SNI) 03-1973-1990, Metode pengujian berat jenis dan penyerapan air agregat kasar

[12] Standart Nasional Indonesia (SNI) 03-6815-2002, Tata cara mengevaluasi hasil Uji Kekuatan Beton. 
[13] Standart Nasional Indonesia (SNI) 15-2049-2004, Semen Portland

[14] Tjokrodimuljo, K. (2009). Teknologi Beton. Naviri.Yogyakarta.

[15] Tri Mulyono. (2003). Teknologi Beton, Penerbit Andi, Yogyakarta

[16] Standart Nasional Indonesia (SNI) 03-0691-1996, Tentang buku beton paving Block. 